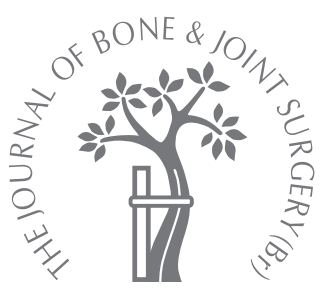

G. Y. Laflamme,

J. Delisle,

D. Rouleau,

A.-P. Uzel,

S. Leduc

From the University

of Montreal,

Montreal, Canada

\title{
Lateral compression fractures of the superior pubic ramus with intra-articular extension
}

\begin{abstract}
A total of 30 patients with lateral compression fractures of the pelvis with intra-articular extension into the anterior column were followed for a mean of 4.2 years (2 to 6), using the validated functional outcome tools of the musculoskeletal function assessment and the short-form health survey (SF-36). The functional outcome was compared with that of a series of patients who had sustained type-B1 and type-C pelvic fractures. The lateralcompression group included 20 men and ten women with a mean age of 42.7 years (13 to 84) at the time of injury.

Functional deficits were noted for the mental component summary score $(p=0.008)$ and in the social function domain $(p<0.05)$ of the SF-36. There was no evidence of degenerative arthritis in the lateral-compression group. However, they had high functional morbidity including greater emotional and psychological distress.
\end{abstract}

The most common injury to the pelvic ring is the type-B2 lateral compression fracture. ${ }^{1}$ According to Tile, ${ }^{2}$ the prognosis is excellent with minimal long-term effects. Open reduction and internal fixation (ORIF) is rarely indicated and the recommended treatment is bed rest with delayed weight-bearing. ${ }^{2-5}$ With the advent of validated measurement instruments, post-traumatic deficits in physical, social and emotional function can be quantified. ${ }^{6}$ However, when describing the prognosis of lateral compression injuries, few studies have used such tools.

Steinitz et $\mathrm{al}^{7}$ observed that many factors influenced the prognosis, including the type of fracture of the ramus with high superior fractures having a poorer outcome than those of the inferior ramus. The former often enter the hip and, although they are regarded as fractures of the pelvic ring rather than of the acetabulum ${ }^{8}$ this low extension into the anterior-column is commonly overlooked as an acetabular fracture. According to Tile, ${ }^{8}$ the articular involvement is rarely sufficiently displaced to require open reduction and is unlikely to affect the function of the hip. Apart from clinical impression of outcome, there have been no previous studies documenting the functional outcome of these injuries.

Our aim therefore was to evaluate the outcome of lateral compression injuries of the pelvis with intra-articular extension.

\section{Patients and Methods}

We identified 30 lateral compression fractures with intra-articular extension into the ipsilateral acetabulum (lateral compression/anterior column group) which had been treated between 1996 and 2000 at our level-one trauma centre. Ethical approval had been obtained from our institutional review board. There were 20 males and ten females with a mean age of 42.7 years (13 to 84 ; Table I) at the time of injury.

Anteroposterior plain pelvic radiographs and Judet views had been taken in all patients at the initial presentation and CT scans obtained after they had been resuscitated and closed reduction of any dislocation of the hip carried out. Any stabilisation of the pelvic ring depended on the anterior and posterior pelvic fractures as well as on the nature of any associated injuries, especially urological and neurological. Of the 30 patients, 27 had been treated conservatively and allowed to mobilise with toe-touch weight-bearing on the injured side for six weeks. Their weightbearing status was then re-evaluated and allowed to increase based on the clinical and radiological findings. Patients who had undergone operation had been given perioperative antibiotics for 24 to 48 hours after surgery and Coumadin or low-molecularweight heparin was used as thromboembolic prophylaxis until discharge home from either hospital or in-patient rehabilitation. All the 
Table I. The clinical details and injury characteristics of the 30 patients with lateral compression/anterior column (LC/AC) fractures

\begin{tabular}{|c|c|}
\hline & Type LC/AC \\
\hline Number of cases & 30 \\
\hline Mean (range) age in years & 42.7 (13 to 84$)$ \\
\hline Male gender (\%) & $20 \quad(66.7)$ \\
\hline Number of comorbidites (\%) & $18(60)$ \\
\hline 0 & 3 \\
\hline 1 & 3 \\
\hline$\geq 2$ & 12 \\
\hline Mean ISS ${ }^{*}(\mathrm{SD})$ & $28.9(10.0)$ \\
\hline Mean $\mathrm{GCS}^{\dagger}$ (SD) & $13.2(3.6)$ \\
\hline Mean time to treatment in days (SD) & $4.7(6.4)$ \\
\hline Number who have conservative treatment (\%) & $27 \quad(90)$ \\
\hline \multicolumn{2}{|l|}{ Numbers with associated injuries (\%) } \\
\hline Head & $14(46.7)$ \\
\hline Spine & $6(20.0)$ \\
\hline Chest & $15(50.0)$ \\
\hline Abdomen & 10 (33.3) \\
\hline Upper limb & $10(33.3)$ \\
\hline Lower limb & $7(23.3)$ \\
\hline Hip dislocation & $2(6.7)$ \\
\hline Initial nerve deficit & 0 \\
\hline
\end{tabular}

patients were assessed clinically at six and 12 weeks, at six months and then yearly thereafter.

The clinical details, the characteristics of the injury, associated injuries, details of treatment, complications and the length of hospital stay were collected from the records by two independent observers (JD, DR). The functional outcome was measured using the musculoskeletal function assessment (MFA) $)^{9-12}$ and the 36-item short-form health survey $(\mathrm{SF}-36)^{13}$ questionnaires. The MFA is a validated 101-item self-administered health status instrument designed to detect differences in function after traumatic musculoskeletal injuries ${ }^{9-12}$ and has been shown to perform well in patients with acetabular fractures. ${ }^{13,14}$ The score is calculated using the recommended algorithm and ranges from 0 to 100 , with a lower score suggesting a better outcome. ${ }^{11,12}$ The SF-36 is a well-established and validated general-health status measurement ${ }^{15,16}$ used to elicit perception of disability, pain and emotional state and for which there are now Canadian normative values. ${ }^{17}$ If these were not returned within two weeks, at least two attempts were made to contact each patient by telephone. If any patients had moved, we attempted to locate them by contacting the last-known family physician and any relatives listed in the hospital records.

Two orthopaedic fellows, not involved in patient management and blinded to the outcome, reviewed the immediate post-operative radiographs and those at the final follow-up. If there was uncertainty about a parameter, the reviewers sought the opinion of the senior co-author (GYL), who was also blinded to the identity of the patients. Pre-operative assessment of the fracture was made from anteroposterior, inlet/outlet, and Judet views along with CT scans if available. The pelvic fractures were classified according to Tile, ${ }^{18}$ the sacral fractures according to Denis, Davis and Comfort, ${ }^{19}$ and the acetabular fractures according to Letournel..$^{20}$ Post-operative films were reviewed for residual displacement of the fracture according to the classification of Matta and Merritt ${ }^{21}$ within two weeks of surgery, at one year and at the final follow-up. All articular displacement was considered, including step deformity. The final follow-up radiographs were used to assess the grade of osteoarthritis (OA), if present, using the method of Kellgren and Lawrence, ${ }^{22}$ the grade of heterotopic ossification according to Brooker et $\mathrm{al}^{23}$ and the presence or absence of avascular necrosis (AVN). ${ }^{20}$

Statistical analysis. This was performed using SPSS version 14.0 (SPSS Inc., Chicago, Illinois). Routine descriptive statistics were used to describe the clinical characteristics and the functional and radiological outcome. Bivariate comparisons were made using the Pearson chi-squared test for dichotomic data and continuous data means were analysed using Student's $t$-test. The MFA scores were compared with published population reference values. ${ }^{12-14}$ The mean standardised z-scores of the SF-36 were also compared with published reference values for the normal Canadian population. ${ }^{17} \mathrm{~A}$ p-value $\leq 0.05$ was considered to be statistically significant. We also compared the functional outcome of the study group with that of other patients with pelvic injuries in our database, including those with type-B and typeC fractures (other group).

\section{Results}

The mean duration of follow-up was 4.2 years (2 to 6). Most patients had two or more pre-existing comorbidities. A motorised vehicle has been involved in 21 of the 30 cases $(70 \%)$. The mean injury severity score ${ }^{24}$ (ISS) was 28.9 (6 to 75 ) and 14 patients (46.7\%) had an associated head injury, which was generally mild with a mean Glasgow coma scale ${ }^{25}$ (GCS) of 13.2 (2 to 15). A total of 28 patients $(93.3 \%)$ had considerable associated injuries, of whom seven $(23.3 \%)$ had a musculoskeletal injury of a lower limb (Table I).

Most patients were treated conservatively with progressive weight-bearing after six weeks. Seven had mild discomfort in the affected groin. Posterior pain was a concern in 11 patients $(36.7 \%)$, but only six considered this severe enough to need occasional analgesia.

Only three patients $(10 \%)$ required surgery. Of these, two underwent ORIF of the pelvis and one an ilio-inguinal approach to address a grossly displaced fracture of the superior ramus with comminution of the anterior column. Fixation was achieved using pelvic reconstruction plates. No post-operative complications were observed. No 
Table II. Details of the functional outcome in 18 patients with lateral compression/anterior column (LC/ AC) fractures

\begin{tabular}{|c|c|c|c|}
\hline Number of patients ${ }^{*}$ & LC/AC & Other group & p-value \\
\hline Number of patients & 18 & 74 & $\mathrm{NA}^{\dagger}$ \\
\hline \multicolumn{4}{|l|}{ SF- $36^{\ddagger}$} \\
\hline Physical component summary & $-1.89(-5.03,1.52)$ & $-2.47(-6.44,0.89)$ & 0.185 \\
\hline Mental component summary & $-1.50(-4.21,0.12)$ & $-0.56(-5.28,1.97)$ & $0.008^{\S}$ \\
\hline Physical function & $-2.12(-5.16,1.58)$ & $-2.27(-6.62,0.61)$ & 0.789 \\
\hline Role physical & $-0.76(-3.42,0.95)$ & $-1.16(-3.42,0.69)$ & 0.312 \\
\hline Bodily pain & $-1.16(-2.58,1.17)$ & $-1.23(-3.65,1.16)$ & 0.836 \\
\hline General health & $-1.01(-4.14,0.93)$ & $-1.01(-4.70,1.43)$ & 0.885 \\
\hline Vitality & $-1.34(-3.83,1.81)$ & $-1.01(-4.45,1.66)$ & 0.374 \\
\hline Social function & $-1.46(-4.39,0.73)$ & $-0.69(-4.49,0.85)$ & $0.043^{\S}$ \\
\hline Role emotional & $-1.24(-4.01,0.59)$ & $-1.07(-3.15,0.63)$ & 0.885 \\
\hline Mental health & $-1.07(-3.84,1.50)$ & $-0.63(-5.20,1.35)$ & 0.345 \\
\hline \multicolumn{4}{|l|}{ MFA" } \\
\hline Overall & $40.50(1.00,76.00)$ & $35.77(1.00,82.00)$ & 0.422 \\
\hline Mobility & $51.40(0.00,90.00)$ & $45.74(0.00,95.00)$ & 0.446 \\
\hline Fine motor skills & $23.80(0.00,71.43)$ & $7.72(0.00,100.00)$ & $0.003^{\S}$ \\
\hline Home & $50.60(0.00,100.00)$ & $42.00(0.00,100.00)$ & 0.296 \\
\hline Activities of daily living & $20.10(0.00,72.22)$ & $18.10(0.00,94.44)$ & 0.749 \\
\hline Sleep & $49.10(0.00,100.00)$ & $49.10(0.00,100.00)$ & 0.998 \\
\hline Leisure & $69.40(0.00,100.00)$ & $59.10(0.00,100.00)$ & 0.251 \\
\hline Relationships & $32.80(0.00,100.00)$ & $29.60(0.00,100.00)$ & 0.662 \\
\hline Cognition & $37.50(0.00,100.00)$ & $29.10(0.00,100.00)$ & 0.394 \\
\hline Emotional adjustment & $42.93(0.00,88.89)$ & $42.40(0.00,83.33)$ & 0.941 \\
\hline Employment/work & $54.20(0.00,100.00)$ & $49.30(0.00,100.00)$ & 0.692 \\
\hline \multicolumn{4}{|c|}{ * SF-36, short form 36; MFA, musculoskeletal function assessment } \\
\hline \multicolumn{4}{|l|}{ † NA, not available } \\
\hline \multicolumn{4}{|c|}{$\begin{array}{l}\text { ¥SF-36: normalized Z-scores are reported for the } 8 \text { domains and } 2 \text { summary scores; the Z-score value } \\
\text { represents the number of SD above (positive values) or below (negative values) the age- and gender- } \\
\text { matched normal population }\end{array}$} \\
\hline \multicolumn{4}{|l|}{$\S$ statistically significant $(p<0.05)$} \\
\hline II MFA, means with maximum an & val & & \\
\hline
\end{tabular}

patient required delayed ORIF for loss of reduction of the fracture. No secondary procedures were needed.

Radiography of the pelvis showed that $93.3 \%$ (28 of 30 ) of the pelvic fractures had a maximum residual displacement within $10 \mathrm{~mm}$. For the acetabular extension, the residual step-off was within $2 \mathrm{~mm}$ in all patients, with no loss of reduction or late displacement. The anterior column fracture was below the anteroinferior iliac spine, seen typically with high fractures of the superior pubic ramus. The roof arc was more than $45^{\circ}$ in all fractures. Comminution was seen in six fractures $(20 \%)$. There was no radiological evidence of OA, HO or AVN in any patient at the latest follow-up.

Of the 30 patients, $18(60 \%)$ completed the SF-36 and MFA questionnaires at a minimum period of two years after injury. The mean overall MFA score (Table II) was not statistically different between the lateral compression/ anterior column group and the other group. The former had a particularly good score for fine motor skills (mean $23.80 ; 0.0$ to 71.4 ) which was statistically different from that of the other group (mean 7.72 (0.00 to 100.00, $\mathrm{p}=0.003))$. Functional deficits were noted for the mental component summary score $(p=0.008)$ and in the social function domain ( $p=0.043$ ) of the SF-36 (Table II).

\section{Discussion}

The prognosis of lateral compression fractures is excellent with minimum long-term effects. ${ }^{2,26}$ When describing the prognosis of these injuries, few reports have used validated functional outcome tools. Gruen et $\mathrm{al}^{27}$ used the sickness impact profile when describing the functional outcome after type-B and type-C fractures of the pelvic ring. Although their results did not reach statistical significance, type-B2 and type-B3 injuries had the least disability. The MFA and the SF-36 were used by Kreder ${ }^{28}$ in a series of pelvic injuries with follow-up of two years. Type-B1 fractures had results comparable with those of type-C fractures. Our findings did not compare favourably with these. ${ }^{28}$ In this study $^{28}$ the type-B2 subgroup obtained an overall MFA score of 29.9 compared with 40.50 in our lateral compression/anterior column group.

Steinitz et $\mathrm{al}^{7}$ undertook a retrospective study of all patients with fractures of the pubic ramus seen in a level-one trauma centre. Patients were grouped according to the site of 
the fracture. The Harris hip score and MFA (short form) were used for assessment. Both scores indicated that patients with high fractures of the superior pubic ramus had significantly poorer function compared with those with fractures of the inferior ramus. Theoretically, extension of the high fracture into the acetabulum could lead to arthritis of the hip. However, our study does not support this presumption. Others have suggested a more aggressive approach in order to achieve a better outcome. Bellabarba, Ricci and Bolhofner ${ }^{29}$ observed the results of the use of an external fixator in the treatment of displaced vertically stable lateral compression fractures and concluded that it was highly effective with the advantage of allowing early mobilisation.

No previous studies have used validated outcome instruments to measure function after lateral compression fractures with anterior column extension. Our study gives reference values for the use of the SF-36 and MFA in the evaluation of such patients. The follow-up MFA scores for our patients indicated that there was profound functional impairment compared with the population reference values reported by Martin et $\mathrm{al}^{9}(\mathrm{p}<0.001)$, suggesting that return to a pre-injury functional level is uncommon. The mean standardised z-scores of the SF-36 were significantly worse than those for the age- and gender-matched normal Canadian population $(\mathrm{p}<0.0001) .{ }^{17}$

It is unclear why the mean mental component summary score of the SF-36 was worse for those in the lateral compression/anterior column group $(\mathrm{p}=0.008)$. Patients with pelvic or acetabular fractures not requiring operative treatment may not see a specialist surgeon, are discharged sooner and typically are not followed as regularly as those who have had surgery. It is possible that they have questions or concerns which are never addressed. Previous research has suggested that patients with greater emotional or psychological distress are less likely to use active coping strategies, which include seeking social support and actively managing their medical condition. ${ }^{30,31}$

It has been pointed out that $50 \%$ of adults with isolated orthopaedic limb injuries meet the diagnostic criteria for post-traumatic stress disorder. ${ }^{32}$ This incidence may be higher in polytraumatised patients. Other studies have shown an incidence of $45 \%$ of mental depression after orthopaedic injury ${ }^{33}$ and Harris et $\mathrm{al}^{34}$ demonstrated that chronic pain after a major motor-vehicle accident was predicted more by psychosocial than by physical factors. Similar studies have indicated that the initial psychological reaction is related to increased pain for up to two months after the fracture ${ }^{35}$ and that psychological support has been shown to be efficient in improving symptoms. ${ }^{36}$ Patients undergoing conservative treatment who receive less support may show higher psychological distress despite a lower severity of injury.

As in most observational studies, our study was limited by the possibility that the results were due to unmeasured variables. In addition, only $60 \%$ of the patients contributed to the assessment of functional outcome. If there was a systematic loss to follow-up this could have led to an overor underestimation of the functional deficit.

Extension of lateral compression fractures into the acetabulum did not induce degenerative arthritis at mid-term follow-up. However, this subgroup of patients had a high functional morbidity, including greater emotional and psychological distress. All patients, especially those treated conservatively, may benefit from a programme designed to enhance coping strategies. Future research regarding the type and intensity of the clinical care of all patients with pelvic injuries is needed if functional deficits are to be reduced.

No benefits in any form have been received or will be received from a commercial party related directly or indirectly to the subject of this article.

\section{References}

1. Tile M. Describing the injury: classification of pelvic ring injuries. In: Tile M, ed. Fractures of the pelvis and acetabulum. Third ed: Philadelphia: Lippincott Williams \& Wilkins, 2003:130-67.

2. Tile M. Management of pelvic ring injuries. In: Tile $M$, ed. Fractures of the pelvis and acetabulum. Third ed. Philadelphia: Lippincott Williams \& Wilkins, 2003:169-202.

3. Tile M, Pennal GF. Pelvic disruption: principles of management. Clin Orthop 1980;151:56-64.

4. Pohlemann T, Bosch U, Gansslen A, Tscherne H. The Hannover experience in management of pelvic fractures. Clin Orthop 1994;305:69-80.

5. Yang AP, lannacone WM. External fixation for pelvic ring disruptions. Orthop Clin North Am 1997;28:331-44.

6. Kreder H, Wright JG, McLeod R. Outcome studies in surgical research. Surgery 1997;121:223-5

7. Steinitz D, Guy P, Passariello A, Reindle R, Harvey EJ. All superior pubic ramus fractures are not created equal. Can J Surg 2004;47:422-5.

8. Tile M. Describing the injury: classification of acetabular fracture. In: Tile M, ed. Fractures of the pelvis and acetabulum. Third ed. Philadelphia: Lippincott Williams \& Wilkins, 2003:427-75.

9. Martin DP, Engelberg R, Agel J, Snapp D, Swiontkowski MF. Development of a musculoskeletal extremity health status instrument: the Musculoskeletal Function Assessment instrument. J Orthop Res 1996;14:173-81.

10. Engelberg R, Martin DP, Agel J, et al. Musculoskeletal Function Assessment instrument: criterion and construct validity. J Orthop Res 1996;14:182-92.

11. Martin DP, Engelberg R, Agel J, Swiontkowski MF. Comparison of the Musculoskeletal Function Assessment questionnaire with the Short-Form-36, the Western Ontario and McMaster Universities Osteoarthritis Index and the Sickness Impact Profile health-status measures. J Bone Joint Surg [Am] 1997;79-A:1323-35.

12. Engelberg R, Martin DP, Agel J, Swiontkowski MF. Musculoskeletal Function Assessment: reference values for patient and non-patient samples. J Orthop Res 1999;17:101-9.

13. Moed BR, Yu PH, Gruson KI. Functional outcomes of acetabular fractures. J Bone Joint Surg [Am] 2003;85-A:1879-83.

14. Kreder HJ, Rozen N, Borkhoff CM, et al. Determinants of functional outcome after simple and complex acetabular fractures involving the posterior wall. J Bone Joint Surg [Br] 2006;88-B:776-82.

15. Ware JE Jr, Sherbourne CD. The MOS 36-item short-form health survey (SF-36). I: conceptual framework and item selection. Med Care 1992;30:473-83.

16. Stewart AL, Hays RD, Ware JE Jr. The MOS short-form general health survey: reliability and validity in a patient population. Med Care 1988;26:724-35.

17. Hopman WM, Towheed T, Anastassiades T, et al. Canadian normative data for the SF-36 health survey: canadian Multicentre Osteoporosis Study Research Group. CMAJ 2000;163:265-71.

18. Tile M. Fractures of the acetabulum. In: Rockwood CA Jr, Green DP, Bucholz RW, Heckman JD, eds. Rockwood and Green's fractures in adults. Vol. 2. Fourth ed. Philadelphia: Lippincott-Raven, 1996:1617-58.

19. Denis F, Davis S, Comfort T. Sacral fractures: an important problem: retrospective analysis of 236 cases. Clin Orthop 1988;227:67-81.

20. Letournel E. Surgical fixation of displaced pelvic fractures and dislocations of the symphysis pubis (excluding acetabular fractures). Rev Chir Orthop Reparatrice Appar Mot 1981;67:771-82 (in French).

21. Matta JM, Merritt P0. Displaced acetabular fractures. Clin Orthop 1988;230:83-97.

22. Kellgren JH, Lawrence JS. Radiological assessment of osteoarthritis. Ann Rheum Dis 1957;16:494-501. 
23. Brooker AF, Bowerman JW, Robinson RA, Riley LH Jr. Ectopic ossification following total hip replacement. J Bone Joint Surg [Am] 1973;55-A:1629-32.

24. Garber BG, Herbert PC, Wells G, Yelle JD. Validation of trauma and injury severity score in blunt trauma patients by using a Canadian trauma registry. J Trauma 1996:40:733-7.

25. Wijdicks EF. Clinical scales for comatose patients: the Glasgow Coma Scale in historical context and the new FOUR scale. Rev Neurol Dis 2006;3:109-17.

26. Koval KJ, Aharonoff GB, Schwartz MC, et al. Pubic rami fracture: a benign pelvic injury? J Orthop Trauma 1997:11:7-9.

27. Gruen GS, Leit ME, Gruen RJ, et al. Functional outcome of patients with unstable pelvic ring fractures stabilized with open reduction and internal fixation. J Trauma 1995;39:838-44.

28. Kreder HJ. Outcome after pelvic ring injuries in adults. In: Tile $M$, ed. Fractures of the pelvis and acetabulum. Third ed. Philadelphia: Lippincott Williams \& Wilkins, 2003:409-16.

29. Bellabarba C, Ricci WM, Bolhofner BR. Distraction external fixation in lateral compression pelvic fractures. J Orthop Trauma 2000;14:475-82.
30. Moneyham L, Hennessy M, Sowell R, et al. The effectiveness of coping strategies used by HIV-seropositive women. Res Nurs Health 1998;21:351-62.

31. Snow-Turek AL, Norris MP, Tan G. Active and passive coping strategies in chronic pain patients. Pain 1996;64:455-62.

32. Starr AJ, Smith WR, Frawley WH, et al. Symptoms of posttraumatic stress disorder after orthopaedic trauma. J Bone Joint Surg [Am] 2004;86-A:1115-21.

33. Crichlow RJ, Andres PL, Morrison SM, Haley SM, Vrahas MS. Depression in orthopaedic trauma patients: prevalence and severity. J Bone Joint Surg [Am] 2006;88-A:1927-33.

34. Harris IA, Young JM, Rae H, Jalaludin BB, Solomon MJ. Predictors of posttraumatic stress disorder following major trauma. ANZ J Surg 2008;78:583-7.

35. Jelicic M, Kempen GI. Do psychological factors influence pain following a fracture of the extremities? Injury 1999;30:323-5.

36. Ehlers A, Clark DM, Hackmann A, et al. A randomised controlled trial of cognitive therapy, a self-help booklet, and repeated assessments as early interventions for posttraumatic stress disorder. Arch Gen Psychiatry 2003;60:1024-32. 